\title{
A IDEOLOXÍA DA XENERACIÓN NÓS
}

\author{
Por \\ CARLOS BALIÑAS FERNÁNDEZ
}

Fálase lexítimamente de xeneración cando un grupo de individuos cumple estas tres condicións: 1) ser coetáneos, 2) ter un referente histórico común, 3) compartir un corpus de opinións, valores, estilos e xeitos de reaccionar cara o ambente. Todo, por descontado, salvando as diferencias de persoa a persoa.

Por se cumpliren estas condicións está xustificado que falemos de «Xeneración Nós». Os intelectuáis que se incluien nela

1) naceron na década dos 80 do século XIX.

2) responderon para Galicia á efervescencia do nacionalismo que en Europa se producíu de resultas da Primeira Guerra Mundial. Mesmo por esa influencia bautizaron co rubro de nacionalismo o sentimento de «nostridade ${ }^{1}$ que, de antes, había na súa e nosa Terra.

3) compartían un mínimo ideolóxico suficiente para unilos, a pesar das normáis diferencias de matices e de xeitos ${ }^{2}$.

Sentíanse, ademáis, grupo xeneracional. O título «Nós», da revista epónima, anque se dirixía a concienciar aos galegos de sermos «Nós»

\footnotetext{
${ }^{1}$ Nostridade, derivado do latín noster/nostra. Chamo así, a falta de palabra máis axeitada, o sentimento de grupo, tan acentuado neste caso que os da Xeneración puxéronlle Nós á revista que resultou epónima.

${ }^{2}$ Acerca de se cabe falar en rigor de «Xeneración Nós» ocupeime no Limiar do meu libro Pensamento Galego-I (Vigo, Sept, 1977), que ven ser unha Antoloxía da Xeneración Nós.
}

"CUADERNOS DE ESTUDIOS GALLEGOS", Tomo XLVII, Fascículo 112, Santiago 2000. 
(mesmos), designaba de primeiras ao grupo que a facía. Abonda, para decatármonos, con ler a presentación titulada «Primeiras verbas», anónima, pero sábese que da autoría de Vicente Risco,o seu director. Que, dentro dese macrogrupo, se diferenciasen dous máis miudos por razón de veciñanza e actuación non anula que os dous pertenezan ao mesmo grupo xeneracional. Un deses subgrupos xurdeu arredor das Irmandades da Fala (Coruña, 1916) e tuvo como asento territorial A Coruña e Santiago. O outro xiraba arredor da revista Nós (Ourense, 1920) que se facía en Ourense e Pontevedra. Sen embargo, acabarían colaborando (Vicente Risco, promotor da revista, pasou a ser o «Conselleiro Supremo» das Irmandades) e ambos grupos confluirían no Partido Galeguista (1931).

A facilitar a concordancia contribuía mesmo o que pertenecían a unha mesma clase social e que algúns exercesen as mesmas profesións. Procedían da clase media e foron maiormente profesores de Ensino Medio (Otero Pedrayo, Losada Diéguez, Risco...) ou funcionarios con tempo libre para adicarse ás suas aficións (Castelao, Cuevillas). Considerados polo seu medio ambiente un chisco raros mesmo por eso de falaren galego (coas suas familias veríanse obrigados a falaren castelán), gozaban de creto, pero de pouco poder. Tiñan en alta estima os valores moráis, entre eles a amistade. Cando decían que traballaban por puro amor á sua Terra, hai razóns para creerllelo: dos seus traballos non obtiñan proveito material algún. Eran persoas con tanta máis aficións á cultura canto que non lle sacaban outro beneficio que o goce personal e a sona que lles podía dar no seu respectivo ambiente. Cómo estas persoas, solitarios en pequenas cidades que eran illas nun medio social agrícola, lían libros extranxeiros e estaban ao tanto do que se sentía e se debatía por Europa é algo que sorprende e que fala moito ao seu favor.

Dado que o estudio que presento está sometido a límites externos de tempo e espacio, o propio estudio ha de limitar tamén o tema se ha de consistir nalgo máis ca en repetir tópicos e datos sabidos. E compre advertilos xa antes de entrar no tema, non sexa que se demande do autor o que el xa non se propuso.

1) Límites de tema. Será a ideoloxía e, precisamente, a organización interna de doutrinas, valores, etc, deixando fora as actuacións políticas.

2) Límites de cronoloxía. A Xeneración somente tuvo actividade ideolóxico-política como grupo nun período de vinte anos aproximadamente (entre 1917-1936) e aínda dentro dese período, houbo unha pausa ou pe-

"CUADERNOS DE ESTUdiOS GALLEGOS", Tomo XLVII, Fascículo 112, Santiago 2000. 
ríodo ralentizado, a causa da Dictadura de Primo de Rivera (1923-1930). En consecuencia, quedan somente dous sexenios de actividade vizosa. Sempre en Galiza, comenzado no 1937, pecha o pensamento da Xeneración e pecha tamén o límite deste estudio. Da posición ideolóxica de cada quen antes de ingresar no movimento así como da que adoptase como consecuencia da Guerra Civil xa non me ocuparei. Moito menos aínda, de continuadores e máis epígonos.

3) Límites de relevancia: Dos coetáneos ocupareime somente dos relevantes desde o punto de vista da ideoloxía, medindo a relevancia por orixinalidade e máis influencia. Sendo inevitable facer escolma, quedareime con Vicente Risco, Castelao, Otero Pedrayo, Antón Villar Ponte, Losada Diéguez. Viqueira morreu demasiado axiña e non tuvo ocasión de participar nos debates ideolóxicos. Ramón Villar Ponte e López Cuevillas só interesan ocasionalmente.

Se algún interés merece o presente estudio, deberase a que, en lugar de resume ou paráfrase, aspira a ser interpretación según claves declaradas. De ser interpretación non se libra tampouco nin o resume mais literal e presuntamente obxectivo -xa a selección dependerá da subxectividade do seleccionador-, pero a presente interpretación faise conforme a claves conscientes e que se declaran. ¿Subxectiva, entonces? Unha interpretación pode resultar mais «obxectiva» do que un resume ou unha paráfrase, porque a obxectividade dunha paráfrase pode no pasar de se corresponder coa literalidade, mentras que unha interpretación pódese corresponder con outro tipo de obxecto: co esprito, co nivel oculto do seu pensar, previo á expresión e corresponderse tamén nivel semántico dos lectores das suas palabras, que estamos noutro periodo histórico.

\section{ENFOQUES NO ESTUDIO DAS IDEOLOXÍAS}

Todos o sabemos e aceptamos: a Xeneración Nós creou e artellou a ideoloxía do nacionalismo galego.

Os aspectos históricos xa teñen sido ben estudiados ${ }^{3}$. Da ideoloxía política tamén se ten tratado dabondo. En cambio, para o meu ver, falta un

\footnotetext{
${ }^{3}$ Estudios de Beramendi, Xavier Castro, Máiz, etc. Polo carácter sintético e panorámico do presente traballo non é posible entrar en citas nin debates.
}

"CUADERNOS DE ESTUDIOS GALLEGOS", Tomo XLVII, Fascículo 112, Santiago 2000. 
estudio de conxunto que sistematice as suas ideas básicas encol de Galicia como unidade física e cultural, como etnia. Para encetar o asunto compre determinar en qué acepción tomo a palabra. Descartada a acepción etimolóxica dos filósofos que crearon este neovocablo no século XVIII (Destut de Tracy e outros), compre engadir que tampouco tomo a verba na acepción peiorativa dos marxistas -ideas que disfrazan intereses-. Emprego a voz na acepción neutral equivalente a ideario ou conxunto de ideas directrices e de valores nos que se apoia un grupo para a sua acción de influencia sobre a sociedade. Anque non toda ideoloxía sexa direitamente política, hainas políticas e o nacionalismo está entre elas. Con todo, nin tan siquera unha ideoloxía política se reduce a ser acólito da praxe política. Certo, pode ocurrir que, co paso do tempo, unha ideoloxía se faga tópico e xa non pase de xustificación meramente verbal para unas realidades políticas, de Realpolitik. Eso se ten dito da ideoloxía comunista da URRS despois que rematou a época da Revolución e se perdeu o idealismo revolucionario: estaría sendo mero instrumento dunha $\mathrm{No}$ menklatura para manterse no poder. Sin embargo, non cabe dúbida honrada de que os comunistas que fixeron a Revolución de 1917 creían no que decían e tiñan un sincero sentimento de estaren traballando en pro dos sectores máis pobres da poboación. Todo nacionalismo, pero en particular un nacionalismo de etnia, xurde e mantense por una vivencia cultural, anque dunha cultura apegada aos factores máis biolóxicos e telúricos: a terra, a comunidade de sangue ou de veciñanza. Como consecuencia desa vivencia virá a demanda de autogoberno e sólo ao cabo da serie chegará a acción política.

Como para calquera outro caso semellante, caben tres enfoques para o noso. O historiador ha de enxergar o asunto desde os sucesos, xunto con seus antecedentes e consecuencias. As ideas importaranlle en canto resultantes e causantes das realidades. A consecución dun Estatuto de autonomía, por exemplo, será cuestión relevante. O politólogo verá o mesmo desde categorías políticas. Importaranlle as ideas en canto determinantes de relacións de poder, en canto tipo de nacionalismo diverso doutros, etc. Sendo o político o factor máis visible e rechamante, enfoque semellante aos do historiador e máis do politólogo será o que adopte calquera que non teña perspectiva particular. Tales enfoques son lícitos e útiles, pero comenzan polo cabo. 
Outros enfoques comezan polo inicio do proceso, pola conciencia do axente. $\mathrm{O}$ antropólogo ocúpase de cómo se vivencia ou interiorizan os feitos, de cómo se distribue anímicamente o espacio, da xerarquía de valores, do papel do real e máis do simbólico, e temas así. Neste caso o antropólogo estudiará a contribución da Xeneración a que a etnia galega tomase posesión consciente de sí mesma, que os galegos collesen conciencia de seren grupo natural diferenciado.

A contribución do filósofo aproxímase á do antropólogo e non poucas das teses do presente estudio tamén se poderían encasillar dentro da Antropoloxía Cultural. Diferénciase en que se fixa máis no aspecto sistemático das ideas e seguirá os parentescos e compromisos de cada unha. Desde esa perspectiva se vai enxergar aquí a ideoloxía da Xeneración Nós.

Sempre un discurso ideolóxico xurde de estados afectivos difusos e lamiguentos e porque un poder externo opresor encirra a organizar ideas que lexitimen a protesta e endereiten cara unha solución. Tamén o nacionalismo galego xordeu, como todos os nacionalismos de «nación» diluída, de considerar que os galegos estaban aldraxados polo Poder Central. Ora ben, eso non pasa de estímulo. O que importa coñecer é a orixe interna e cómo se articulan as ideas, creencias, valores e actitudes. Por un camiño, eso desembocará en que se articulen as reclamacións en conceptos de Dereito Político e acaban en accións de tipo político (Programas, Partidos, etc.) e máis propagandístico (slogans, manifestos, discursos oratorios, poemas, etc). Por operativo e exterior, eso é o que chama máis atención, pero non tería forza persuasiva e non pasaría de forza cega de non ser porque as reclamacións de autogoberno «casen» co sistema de valores e coas características das xentes da comunidade en cuestión. Tal é o tema especializado do antropólogo. A filosofía por antonomasia diferénciase da ideoloxía en que trascende ás condicións de época e en xeral da particularidade. As ideas teñen a sua forza lóxica e a sua parentela propia. Ténas alguén e, neste senso, son de quen as teña, pero elas propiamente non son nin de ninguén nin de ningures.

Que ambos enfoques -o que se interesa pola eficacia práctica e .o que comenza desde a interioridade-son necesarios e complementarios confírmao o feito de que, desde cada ún, resulte insatisfactorio o outro. A un historiador, a un politólogo, pareceralles que o análise que vou presentar se perde en xeneralidades: ocurre que a eles interésalles a eficacia, que é momentánea, do intre concreto. Pola contra, a un antropólogo cultural e 
máis a un filósofo pareceralles que non se acabará de entender a actuación política en caso de non coñecer a arquitectura interior da ideoloxía. Desde ahí, o antropólogo deterase maiormente no caso particular galego, cos seus vencellos con outros aspectos da alma galega. O filósofo, pola sua banda, tratará de ampliar o panorama fora das coordenadas de espacio e de época. Ao fin, se aínda cincuenta anos despois de ter perdido eficacia política a Xeneración Nós, nos interesamos por ela será porque reborda da época. Foi historia, pero é «histórica» noutra acepción desta verba: na de ter deixado pegada na historia. Pero as súas ideas non xurdiran da nada: tiñan precedentes, eran ecos de ideas compartidas por Europa adiante e os debates aínda seguen abertos.

¿Qué ocorreu exactamente?, ¿qué doutrinas pregoaron? ¿a qué sentimentos apelaban para movilizar? ¿en qué prácticas políticas traduciron esos ideáis? Tales son as preguntas que interesan ao historiador, ao politólogo e a todo aquel que, por non adoptar un enfoque específico, atense ao máis visible e vistoso. ¿Cómo entendían o peculiar da etnia galega? ¿cómo vivenciaban as cousas galegas? Tales son as preguntas específicas do antropólogo cultural ¿Cal é o significado diso?, ¿por qué, cando ese intre histórico xa pasou e non podemos intervir nel, aínda nos interesa por máis que por curiosidade? ¿Qué é o que, ocurrindo nun determinado intre histórico, sobrevive e, por empalmar co pasado e o porvir da comunidade, aínda nos afecta ou merece interesarnos a nós que estamos noutra época?

Compre diferencialos, pero non demostraría moito siso andar á retesía entre enfoques. Xa que son os máis espontáneos e tenden a deixar en sombra os demáis, quede dito que o enfoque político do historiador e máis do politólogo non bastan. Sen o sistema latente interno de creencias e valores, o suceso estudiado queda sin a xustificación suficiente, puro epifenómeno do intre. Unha ideoloxía non acaba de se comprender se nela non se divisa máis ca o que ten de «servicio» ao activismo político. Por outra banda, o suceso vai apegado ao intre determinado, que sucederá e será sucedido por outro intre determinado. Hai historia somente se consideramos que das miríadas de sucesos que ocurren nun intre seleccionamos algúns por iren cara un estado privilexiado ou relevante. Nas ideas hai un aspecto intemporal e un aspecto de tendencia: as tendencias históricas son o colar donde enfiar as perlas, o rosario onde se enfian as doas.

A cada enfoque, cadansúa metodoloxía. Coñecemos as tesis dos autores sobranceiros da Xeneración, pero ¿hai un sistema latente de coinci- 
dencias compartidas que condicionan e prolongan esas manifestacións? Tal é a pregunta á que pretende responder este estudio.

\section{AS FONTES}

Non houbo ningún concilio de Nicea que fixase un Credo. Tampouco houbo un teórico que enunciase un sistema doutrinal tan sistemático que se poidese expoñer en función de tal cuestionario as opinións dos demáis ${ }^{4}$. Os alicerces puxéronos dous breves libros: Nuestra afirmación regional (Ramón Villar Ponte, A Coruña, 1916) e Teoría do nacionalismo galego (Vicente Risco, Ourense, 1920), pero nin tan siquera o folleto deste último, que era catedrático de filosofía, vai máis alá dunha manchea de enunciados: lemas para meditar e movilizar máis ca teses ben argumentadas. Sempre en Galiza (1937-1947) presenta un certo carácter enciclopédico, pero ven ser o epílogo, no que resoan os temas e teimas comunáis. Ese carácter «enciclopédico» pode ser unhas das razóns do éxito deste libro, «Biblia do galeguismo». Outra ven da habilidade do escritor, dono dun estilo rechamante, irónico as veces, lírico outras, de frases cortas e lemas epigramáticos. E a terceira e máis influinte, da biografía e personalidade do autor, que soubo facer dun libro de memorias políticas un programa de futuro. A única virtude que o libro non ten é a orixinalidade doutrinal. Case todas as ideas teóricas que moe Castelao neste libro eran fariña xa moída, maiormente por Risco ${ }^{5}$, anque non o cite por estaren xa

\footnotetext{
${ }^{4}$ Sempre en Galiza ven ser un testamento, como se comprobará polo que direi no texto. En canto a El pensamiento político de Galicia, de Risco, ocúpase máis de tácticas oportunistas naquela hora (1931) que da visión teórica. Esta compre buscala en Teoría do nacionalismo galego, que sin embargo non pasa de folleto programático.

${ }^{5}$ Por eso neste traballo citarei primeiro e máis por longo a Risco ou a Otero que a Castelao. Sempre é cuestión moi problemática dirimir sobre paternidades e prioridades, pero o caso é que, se atendemos aos desenrolos teóricos e non aos lemas epigramáticos, son Risco, Otero, Losada (anque este publicase pouco) e mesmo os irmáns Villar Ponte os que suministran máis material de estudio. O eido no que Castelao fai unha aportación propia, non deudora de ningún do grupo, é o da Estética e de Teoría da arte galega. Tense a impresión de que entre eles repetíanse uns aos outros sin andar á retesia por cuestións de «primoxenitura». O comezo de «Alba de gloria» reproduce literalmente un discurso de Otero Pedrayo (Vigo, 1931) publicado na revista Nós. A pesar de que no texto mesmo hai un «como diría Otero Pedrayo», síguese citando como de Castelao.
}

"CUADERNOS DE ESTUDIOS GALLEGOS", Tomo XLVII, Fascículo 112, Santiago 2000. 
en bandos belixerantes opostos. Desde entonces, por ter Risco desertado de sí mesmo, cando se queren fórmulas autorizadas, adóitase collelas de Castelao e non de Risco. Sen embargo, a imparcialidade (querse decir a parcialidade coa verdade histórica) demanda contar os feitos conforme ao orde no que se sucederon e conforme ao orde cronolóxico se poñerán aquí. Por eso as de Castelao veñen as derradeiras, aínda recoñecendo que acostuman a estar máis nídias.

Non tendo habido un «doctrinario» que presentase sistemáticamente o ideario, o estudioso terá que facer unha ceifa para recoller, xunto coas ideas deses libros citados, unha chea de manifestacións soltas, incompletas unha por unha, ocasionáis, que somente daban o mínimo de teoría necesario para movilizar os ánimos e basear os programas concretos. Artículos en revistas de escasa difusión (Nós, A Nosa Terra), manifestos e discursos políticos, artículos na pouca prensa que aceptaba orixináis en galego, obras literarias, discursos autovindicadores (como Sempre en Galiza). Eso implica que teremos que descontextualizar esas manisfestacións do contexto inmediato e introducilas nun contexto teórico armado polo hermeneuta, anque se éste é honesto, tratará de que se corresponda coas manifestacións deles e deberá probalo con frases literáis. O resto, $\mathrm{o}$ arrecendo das ideas -que non deixa de ser tamén importante- haino que extraer do ambiente emocional que difícilmente pasa ao papel ${ }^{6}$.

Os membros do corpus están ahí, á vista: o corpus mesmo ten que aportalo o estudioso con categorías que poden non coincidir literalmente cos seus programas concretos. Para sorte nosa, o futuro danos outra perspectiva máis longa da que eles podían ter. Nós podemos ver o arco completo onde eles, en cada intre, somente podían divisar un comenzo de curvatura.

As ideas que aquí nos importan son as referentes ao tema galego. As referentes á Visión do Mundo e da Vida importan somente desde a perspectiva biográfica, xa que non fixeron ningunha contribución significati-

${ }^{6}$ Dalgúns persoaxes da Xeneración téñome ocupado por miudo noutras publicacións. Acerca de Otero Pedrayo, pode verse o libro Descubrindo a Otero Pedrayo ( Santiago, Coordenadas, 1991) Acerca de Risco, «A filosofía política de Vicente Risco» (revista Grial, núm. 86, monográfico adicado a Risco, 1984, páx. 402) Acerca de Castelao, o artículo «Castelao, conciencia de Galicia». Revista de Letras. Universidad de Puerto Rico, Recinto de Mayagüez, núm.6, 1970, pp. 218-234.

"CUADERNOS DE ESTUdIOS GALLEGOS", Tomo XLVII, Fascículo 112, Santiago 2000. 
$\mathrm{va}^{7}$. Ademáis, no caso de se enguedellar moito en temas de concepción da vida, xa terían máis peso as diferencias cas coincidencias e o grupo deixaría de selo. Confírmao que tal foi o que ocorreu cando sobre os galeguistas tuveron que tomar decisións por conflictos chegados do exterior. Nos anos 30 toda Europa estaba sendo sacudida polo comunismo e máis o fascismo. En España engadíase, ademáis, a loita pola cuestión relixiosa, con un anticlericalismo que as xentes relixiosas vían como antirrelixioso. Deste xeito, sobre o problema do nacionalismo incidiría -e ao cabo, predominaría- a loita entre Esquerdas e Dereitas. Cando esta liorta se introducise no Partido Galeguista, comprobaríase que, en relación a eses outros puntos exteriores, había entre eles diferencias suficientes como para destragar a unidade: uns eran creentes e outros «indiferentes» e anticlericáis se non declaradamente antirelixiosos, uns eran de Esquerda e outros de Dereita, uns convivían co marxismo e outros fuxían del como do demo, etc. Cando estourou a Guerra Civil, os que entre sí se chamaban irmáns, arredaríanse entre sí. Na loita ideolóxica que seguíu, Risco e Castelao serían belixerantes en bandos opostos.

Por suposto, a nós interésannos mentras foron «Nós» e no que toca á sua definición de Galicia. A Visión do Mundo e da Vida e asunto de cada ún, non da Xeneración. Certo, foi probablemente a que decideu no posicionamento de cada quen nos preliminares da Guerra Civil -polo menos, no caso de Vicente Risco-, pero eso corresponde ás persoas, non ao grupo. De todos modos, compre advertir acerca dun desenfoque frecuente entre historiadores e politólogos verbo dos enfrentamentos ideolóxicos entre os galeguista. Por reducir o seu horizonte ao ámbito doméstico tenden a dar explicacións excesivamente psicolóxicas e personalistas ${ }^{8}$.

\footnotetext{
${ }^{7}$ No excelente libro sobre Otero Pedrayo de Valcárcel e Quintana, estúdiase por miúdo as opinións de Otero Pedrayo sobre o marxismo, o cristianismo, etc. Todo eso estaba xa dito por non galegos.

${ }^{8}$ Tal é o que ten ocurrido maiormente con Vicente Risco. Por non ter en conta o que ocurría en Europa, tense explicado o «caso Risco» como debido somente a motivos de carácter personal (por ter perdido protagonismo, por medo, etc.). Enfrentamentos e arredamentos parecidos estaban a se producir noutros ámbitos xeográfico por motivos semellantes. Non debería ser necesario aludir ao que estaba ocurrindo a nivel español. Mentras Alcalá Zamora, como Presidente do Estado sancionaba oficialmente a Constitución de 1931, declaraba públicamente o seu desacordo cos artículos que consideraba «laicistas» e antirrelixiosos. Cando estalase a Guerra Civil, veríase a xentes de Esquerda procli-
} 
O tópico dí que a Xeneración Nós trazou a ideoloxía do nacionalismo galego. Desde o enfoque adoptado, eso tradúcese nesto outro: intentaron e, en certa medida, conseguiron facer

- dunha fala, unha lingua

- dunha poboación, un pobo

- dun territorio unha Terra

- dun pasado, unha Tradición e máis unha Historia

- dun folklore, unha cultura

Por descontado, non eran soñadores de utopías ni tampouco académicos que, na paz do seu gabinete, analizan unha empresa na que non están comprometidos. Aínda sendo case todos eles literatos, eran tamén activistas que loitaban para que a súa Terra tuvese autogoberno. Cando o Partido Galeguista (1931) concretase esa reclamación pediría un Estatuto de Autonomía dentro dunha España entendida como Unión de Pobos e mesmo Federación Ibérica. Ora ben, esa reclamación non a facían en nome de ventaxas materiáis ou en motivos de xeopolítica. Para eles o autogoberno era unha consecuencia lóxica dun dereito natural xenerado por ser Galicia una etnia ou, como eles preferían decir, una nación. Sendo así, topar as características diferenciáis desa etnia convertíase en asunto moi importante e tal foi a súa principal contribución. Se fracasaron na acción política, nesto tiveron éxito total.

Sen embargo, tiñan un enfoque considerablemente amplio, cousa que a miúdo esquecen os analistas desde enfoque político. Enxergaban o caso galego dende o panorama mundial da época. No tocante ao cultural, soñarían con que a cultura galega aportase a súa voz peculiar á grande sinfonía da cultura universal. Eso era o que se sobreentendía no lema: «Galicia, célula de universalidade». Eran tamén conscientes do conflicto máis gra-

ves ao Bando Nacional e a xentes de Dereita defendendo a República. En Francia estaba ocurrindo daquela cousa parecida (Pode verse o libro La Rive Gauche. La élite intelectual y política en Francia entre 1935 y 1950. Madrid, Planeta, 1996). Nas escisións do Partido Galeguista resoaban as escisións que estaban a producir entre os intelectuáis europeos o comunismo ruso, o fascismo, a loita relixiosa. Risco vivira na Mitteleuropa. Castelao tamén anduvera por Europa. Todos eles .lian moito libro francés e, por suposto, a Unamuno, Ortega y Gasset, etc.

"CUADERNOS DE ESTUDIOS GALLEGOS", Tomo XLVII, Fascículo 112, Santiago 2000. 
ve daquel intre: a loita a morte entre o fascismo e máis o comunismo. Todos eles se manifestarán en contra tanto dun como doutro, anque despois da Guerra Civil Castelao, por caer na zona republicana, cite en Sempre en Galiza a Stalin e deixe as bromas que adoitaba facer do comunismo nos dibuxos de Cousas de vida. Algúns dos grupo (Losada, Risco, Otero) verán no problema social a consecuencia dun industrialismo excesivo e propoñerán como remedio ou, polo menos, como atenuante a «volta á Terra», tema do relato $A$ coutada, de Risco.

Cando non se segue a letra dos autores e se fan paráfrases desde outro enfoque, sempre pode haber quen diga que se cae en vaguedades. Todo dependerá de se o lector repara ou non nas transicións e nos matices. Difícilmente podían eles terse decatado do sistema e formulalo como programa. Somos nós, polo noso distanciamento, os que podemos inferilo a posteriori. $\mathrm{O}$ análise que vai seguir diríxese a marcar as liñas principáis e suliñar a novedade respecto dos precedentes. En cada caso repetirase procedimento: primeiro formularase a tese, despois seguirán por orde cronolóxica algúns textos que a confirmen ${ }^{9}$, tratando de situala dentro do mundo de ideas e dos debates que daquela tiñan lugar por Europa adiante.

\section{OS GRANDES EIXOS DA IDEOLOXÍA}

\section{A) FACER DUNHA FALA UNHA LINGUA}

Evidentemente non se trata agora da clásica diferenciación dos estructuralistas entre fala e lingua. Entendo agora por fala un instrumento de comunicación suficente para expresar as necesidades cotidianas e máis os sentimentos (poesía, literatura), pero non para outros asuntos. Por lingua, entendo unha fala que valla para expresar calquer sector da cultura e que poida usarse no sector oficial (na Administración).

Por este capítulo comenzarei porque era clave para outros: a lingua é o factor diferencial máis forte. De feito a Xeneración comenzou a actuar como grupo en canto literalmente Irmandades da Fala (1917).

\footnotetext{
${ }^{9}$ Os lectores poden queixarse, con razón, de que non dea os datos bibliográficos das citas que faga. Non o permiten os límites de espacio. No caso de o facer, o aparato erudito ocuparía outro tanto espacio como o texto. De moitas destas citas dín os datos noutros traballos monográficos.
}

"CUADERNOS DE ESTUDIOS GALLEGOS", Tomo XLVII, Fascículo 112, Santiago 2000. 
Ramón Villar Ponte, 1916: «Toda afirmación gallega debe partir ineluctablemente del renacimiento del idioma» (Nuestra afirmación regional). Otero Pedrayo, 1931: «A lingua, o primeiro... Mellor unha Galicia pobre que unha Galicia rica usando outra lingua» (Morte e resurrección). Castelao sorprendería ao Congreso dos Diputados na Segunda República coa parábola dos cans, que «aínda están na etapa do idioma universal». En Sempre en Galiza dirá dos partidarios dunha lingua universal que «buscan a perfección baixando pola escala zoolóxica». E apoiará o aserto con este razonamento: «Un idioma non nasce pola vontade xenial dun grupo de homes, nace pola predisposición psicolóxica dun pobo que, en condicións históricas favorables crea unha cultura e a súa correspondente maneira de expresión». Nótese esto de suliñar a correspondencia da lingua coa cultura. Eles aspiran -nada menos- a que a cultura galega sexa unha contribución á cultura universal.

Consonte con eso, farían uso constante e teimudo da lingua galega e axeitaríana para a prosa doutrinal, a linguaxe administrativa, etc. Con todo, a Xeneración iríase da vida activa cunha asignatura pendente: promulgar unha Gramática normativa que unificase os dialectos, como acadaran daquela os cataláns ${ }^{10}$.

\section{B) FACER DUN TERRITORIO, UNHA TERRA}

Territorio, poboación (cidadanía) e soberanía son os factores constituíntes dunha Nación-Estado, segundo a doutrina tópica do Dereito Político.

A Xeneración vai dar ese paso que convirte un territorio -concepto xeográfico- nunha Terra, concepto psicosocial. A Terra dun terrateniente é unha posesión útil, comerciable, que tanto ten que estea localizada nun lugar ou noutro. Cando alguén dí «a miña terra» está sinalando outra cousa moi diversa, por máis que non se distinga físicamente. Está designando algo seu por dereito de propiedade afectiva: é a terra dos seus antergos, da sua infancia, o lugar de acougo, do que se se hacha lonxe sinte saudades e

\footnotetext{
${ }^{10}$ De todos modos, quedou unha proposta (a de Freijomil e Abelardo Moralejo Laso), asisada e que, por maxisterio ou por coincidencia, puxo os alicerces da koiné que, anos máis tarde, acadaría a Editorial Galaxia.
}

"CUADERNOS DE ESTUDIOS GALLEGOS", Tomo XLVII, Fascículo 112, Santiago 2000. 
olla como o lugar onde podería curarse da súa enfermedade psíquica e mesmo somática. A «Terra Nai»"1.

Todo esto tíñano expresado xa unha chea de poetas. Risco ocupouse por longo do sentimento da natureza na cultura galega e faría del un risco diferencial do noso ethos. Algúns membros da Xeneración (Losada, Otero, o mesmo Risco) irían máis alá: viron no abandono crecente da Terra mesmo no senso de agricultura a causa oculta, segreda, de que se tuvera agudizado tanto os conflictos sociáis. Pola sua banda, Otero Pedrayo, non somente fixo exquisitos análises estilísticos da paisaxe, senón que tamén trazou unha excelente teoría da paisaxe. A presentación xeral da teoría faríaa cando xa pasara o período da actuación colectiva do grupo, pero as ideas directrices datan xa daquel tempo ${ }^{12}$.

\section{C) FACER DUNHA COMUNIDADE, UNHA NACIÓN}

Os galegos sentíanse diferentes desde sempre, pero no campo do falar, do festivo, do afectivo, etc. Ser diferente é relativo aos alleos. Neste caso, os españois xa se encargaban de que os galegos se sentiran diferentes ao teren de nos un xuicio que amiudo era despectivo, cariñosamente despectivo. Xa os provincialistas aproveitaron esa sensación difusa de desprecio e marxinación para esguizar entre os seus compatriotas a solidariedade na defensa. Castelao adicará unha parte considerable de Sempre en Galiza ás diferencias e tamén aos presuntos ou efectivos aldraxes. Era unha vella ladaíña que comenzara xa cos «provincialistas»e recollera Rosalía de Castro no prólogo a Cantares Gallegos. O propósito da Xeneración Nós vai ser transformar os feitos diferenciáis en vontade política de afirmar a diferencia. Ben o declaraba o título da obriña de Ramón Villar Ponte que obrou de convocatoria para constituir as Irmandades da Fala: Nuestra afirmación regional. ¡Afirmarse! Para eso era preciso que as xentes galegas se decatasen de seren nos, que adqui-

\footnotetext{
"Teño desenrolado máis este punto nos meus traballos $A$ chamada da terra en Rosalía de Castro e Martin Heidegger (Actas do I Coloquio Luso-Galaico sobre a saudade, Braga, 1966) e Introducción non literaria a Rosalía de Castro (Publicaciones de la Fundación Alfredo Brañas, Santiago 1985).

${ }^{12}$ Pode verse o capítulo «Otero Pedrayo, intelectual» do meu libro Descubrindo a Otero Pedrayo (Santiago, Edit. Coordenadas, 1991). Neste libro e máis na voz «Otero Pedrayo» da Gran Enciclopedia Gallega dín a miña visión de conxunto do noso autor.
}

"CUADERNOS DE ESTUDIOS GALLEGOS", Tomo XLVII, Fascículo 112, Santiago 2000. 
risen conciencia de nostridade. Tense discutido sobre por qué os fundadores da revista Nós, escolleron ese título que iba ser epónimo de todo o grupo xeneracional. ¿Un título meramente afirmador da diferencia? (Un xornal coruñés xa publicaba en 1916 unhas páxinas baixo tal rubro). ¿Unha imitación do Sinn Fein, «nós mesmos» de Irlanda? (A revista adicaría un número monográfico ao tema de Irlanda, daquela de máxima actualidade). Pola presentación anónima, pero da autoría do director, vese que Risco apuntaba a un grupo de persoas. Xa non cabe decir o mesmo cando Castelao titula así daquela un famoso álbum de dibuxos: alí veñen os labregos, os mariñeiros, os funcionarios e tamén «os señoritos». Coma quen di, o retábulo enteiro dun «peto de ánimas». Tratábase de transformar a conciencia de sermos os galegos diferentes en vontade política de reclamar o dereitos inherentes a esa diferencia.

En tal sentido, non somente falarán de sermos os galegos un pobo, senón tamén de sermos nación. Na acepción máis xurídica, pobo equivale a poboación. Nunha acepción máis sociolóxica, son pobo os habitantes non caracterizados por un sinal de «distinción» ou calquera en canto non estea ou non se o considere entre os «distinguidos» (distintos, dise en portugués). Esta é a acepción que rima coa expresión castellana «pueblo llano» e que xoga con «clases populares», ser «popular», «populismo». Noutra acepción xa máis achegada ao campo político designa os membros dunha etnia ${ }^{13}$ versus os membros os membros doutra etnia veciña ou do Estado multiétnico do que forme parte esa etnia. Pobo pertenece ao campo semántico do folklore, do que os alemáns chaman Völkerkunde, da Etnografía e da «Psicología dos pobos».Como caso diacrítico pode valer o ocurrido cando Th. Herzl convocou aos xudeos a formar un Estado Nacional. Moitos xudeos asimilados nos Estados onde os situara a diáspora, recoñecéndose membros do pobo xudeo, negáronse a ser «sionistas»e a formar parte na nación xudea, cuio nome é Israel.

Falar de pobo galego non levaba especial compromiso nin había de suscitar receo, pero, como se sabe, os da Xeneración Nós proclamaron que Galicia e nación e eles mismos proclamáronse nacionalistas. Tamén

\footnotetext{
${ }^{13}$ ¡Outra verba ben ambigua! Os gregos empregábana como sinónimo de raza. «Raza» decíase tamén naquel tempo e dixérono a miúdo os da Xeneración, pero en acepción escasamente racista.
}

"CUADERNOS DE ESTUdIOS GALLEGOS", Tomo XLVII, Fascículo 112, Santiago 2000. 
éste é un concepto cuio significado varía conforme ás as connotacións de cada caso.

Pola sua banda, tamén nación é término fronteirizo, e o seu significado ven definido polas connotacións. Cando os revolucionarios franceses transfiren a soberanía do monarca ao pobo, necesitan fraseoloxía política nova. En lugar de súbdito, dirase en adiante cidadán e, en lugar de Reino, «nación». En consecuencia a voz, aplicada na Idade Media aos alumnos dunha Universidade que eran «naturales» de tal ou cal rexión xeográfica, entraba deste xeito noutro orden de paradigmas e sintagmas. En diante xogaría estructuralmente con República (na acepción de Res Publica), Estado, autonomía ou independencia, etc.

Onde non haxa etnias diferentes e que reclamen diferenciarse políticamente, nación ven ser equivalente de Estado, «comunidade política» independente. Así un filme famoso contou a fundación dos Estados Unidos de América como o «nacimento dunha nación»; pola sua banda, as asociacións de Estados titúlanse «de nacións» (Sociedade de Nacións, Nacións Unidas). Pero o caso de comunidades étnicas dentro dunha comunidade maior que reclaman personalidade xurídica diferencia, obriga a distinguir entre Nación-Estado e nación sumerxida ou diluída, á veces denominada nacionalidade.

En todo caso, os nacionalistas -entre eles os galegos- van tomar nación na acepción máis etimolóxica: lugar e grupo onde se nace, esto é, patria e matria, Vaterland, país dos proxenitores, ese lugar do que ún di ser «natural». Sen embargo, dado que nación implica Estado, caemos no espiñento problema da Nación-Estado, nacionalidade sin Estado, etc.

Que Galicia era nación xa se adiantara a afirmalo Don Manuel Murguía. Manifestárao con ese tipo de enunciados que se presentan como afirmacións dun feito cando están sendo reclamacións, ou sexa, cunha linguaxe que parecendo denotativo é «performativo». «Es un hecho que por el origen, por el territorio y el lenguaje, de igual manera que por su historia y la comunidad de sentimientos y deseos, estos pueblos del noroeste foman una nación con caracteres propios, distinta en gran parte de las que constituyen el Estado español». O razonamento concluía con este epifonema: «Bélgica no tiene más territorio y Suiza no tiene más población»».

Daquela tal afirmación tiña que soar a provocación. Cincuenta anos despois, volvérase tópico entre os nacionalistas, pero na realidade políti- 
ca de España nada cambeara. De ahí que eles tuveran que seguir reafirmando a tese, anque precisando que nación non equivale necesariamente a Estado Nación. «A nación, para nós, é un grupo humán étnicamente diferenciado, que cobre un territorio característico, que fala unha lingua propia e rexe a súa vida moral e física por tradición e costumes peculiares». Como se comproba, Castelao coincide case con Murguía nas condicións para haber nación, anque él para se autorizar cunha «autoridade» prestixiosa cite a Stalin. (Está escribindo na zona republicana, durante a Guerra Civil).

Como case sempre, as manifestacións sobre realidades culturáis completan o seu sentido por aquelo co que lindan ou rivalizan. Para o sistema político democrático-liberal nación é unha comunidade política determinada por intereses e que se fai ou desfai por un contrato social implícito. Para un nacionalista nación é, en palabras de Risco, unha «comunidade de intereses espirituáis e materiáis determinada pola natureza» ${ }^{14}$. E a natureza quen fai a nación, non a vontade dos cidadáns. Risco chega a afirmar que as nacións existen «na idea de Deus».Por eso, cando un nacionalista reclama autodeterminación refírese a que os membros dunha etnia poidan determinarse libremente a ter autogoberno, non naturalmente a disolverse como etnia, porque tal decisión sería contra natura: a etnia xenera obrigas naturáis frente ás que non vale o capricho dos individuos.

Ora ben, Galicia era, para eles, unha nación diluída, sumerxida, á que compre despertar do seu soño, como lembra o mesmo Himno Galego. De ahí a cisma dos homes da Xeneración por topar e afirmar feitos diferenciáis.

Ora ben, unha cousa é estar convencido en teoría de ser Galicia nación e outra, moi diversa, que sexa prudente decilo. O propio Murguía preferira, en lugar de nación, rexión, como decía o rexionalismo de Alfredo Brañas. Aínda en 1916, Ramón Villar Ponte, o promotor das Irmandades da Fala, titulaba (¡en castelán!) o seu libro: Nuestra afirmación regional.

Xa cos precedentes do Nacionalismo vasco e catalán e tendo en conta o prestixio crecente da verba por toda Europa, os da Xeneración Nós, vanlle perder o medo ás resonancias da verba. En 1918 celebrábase en Lugo a primeira «Asamblea nacionalista»: Con todo, por conveniencia de

${ }^{14} \mathrm{O}$ que é unha nación». Artículo de $A$ nosa Terra, recollido na antoloxía de C. Casares: Vicente Risco. Vigo, Galaxia, 1981. páx. 146.

"CUADERNOS DE ESTUDIOS GALLEGOS", Tomo XLVII, Fascículo 112, Santiago 2000. 
aunar votos, xuntar correlixionarios e non provocar adversarios, aínda en 1931, chamaranlle Galeguista e non Nacionalista ao Partido por eles creado. As palabras non sempre son indiferentes.

Como era de esperar, xurdirían matices en canto ao xeito e a presa na demanda. Entre eles haberíaos máis posibilistas e máis puros, máis tácticos e tolerantes coas componendas e tamén outros, máis homes de principios e, por eso, menos tolerantes coas tácticas oportunistas. Xa en 1921 Antón Villar Ponte distinguiría os de «temperamento apostólico« e os de «temperamento político», engandindo por certo que prefería aos primeiros. Xa quedou alegada anteriormente una manifestación sobre da pouca afición de Risco á actividade política cando acababa de entrar nela. Sendo así non pode sorprender que, cando por convenencias electorales, o Partido Galeguista abandase cara o frente popular, Risco se manifestase máis esixente en non transixir con compoñendas. Como se sabe, Risco era culturalista máis ca político.

Décadas máis tarde, o novo nacionalismo da década dos 70 acusaría aos guieiros da Xeneración Nós e ao Partido Galeguista de «culturalistas», esto é, de seren mornos, elitistas e pouco arriscados nas demandas de autogoberno. Estea ou non lexitimada esta acusación, afectaría en todo caso aos aspectos personáis. Hai, en cambio, outro punto que afecta á ideoloxía. Eles eran dos que primaban o cultural sobre o poder fáctico. «Unha nación pode ser tal nación (...) sen autonomía de ningunha clase», escribeu Risco. Diríase que era unha «saída» peculiar de Risco, tan culturalista e pouco amigo da acción política, pero velahí que tamén Castelao, en Sempre en Galiza, despois dunha vida consagrada á actividade política, repetirá case literalmente a Risco (anque sin citalo): «Unha nación pode ser tal sen autonomía de ninguha caste, sempre que o sentimento que a diferencia resulte inasimilable, sempre que se manteñan vivos os atributos que a caracterizan».

En todo caso, as xentes galegas distaban de compartir a ardentía dos seus líderes. Das tres eleccións xeráis a que concurriron durante a Segunda República, os galeguistas conseguiron unha manchea de diputados o ano 1931 e ningunha no ano 1933. Nas eleccións de 1936 conseguiron algunhas actas, pero por ir dentro da coalición chamada Frente Popular. Os galeguistas tiñan moito prestixio moral, pero poucos votos. O Estatuto saeu adiante porque o Partido Galeguista puxera como condición para entrar na coalición electoral do Frente Popular que se éste gañaba, convo- 
caría o plebiscito. A votación gañouse, anque non sen que fose necesario «meter man» (a man esquerda, naturalmente) nas urnas.

A pelexa semántica arredor da palabra escandaleira-Nación-dista de ter terminado. Indicio de que, cando de ideoloxías se trata, rara vez as verbas son inocentes. Cada quen xoga con cartas marcadas, porque conta coas connotacións afectivas mesmo cando emprega o frío tono do linguaxe denotativo.

\section{D) FACER DO PASADO UNHA HISTORIA}

Historias do Reino de Galicia xa se escribiran no Antigo Réximen. Historias de Galicia somentes as había desde a etapa provincialista (Vicetto, Murguía, Padín, Verea y Aguiar). Non se eliminou o de reino porque tivera desaparecido a monarquía: España seguía gobernada por reis. No cambio de título - de Galicia e non do Reino-iba implícita outra cousa: ¿quén é o suxeito e cal é o horizonte dos sucesos históricos? Escribir «de Galicia» implicaba recoñecer que Galicia tiña historia de seu, non a título de parte dun todo maior. Ninguén da Xeneración fixo unha aportación relevante de conxunto neste eido (Anque Risco escribira un pequeno manual de Historia de Galicia, non pasou de resumir a Murguía). En cambio, matinarían non pouco con mentes de clarificar o cerne dese suxeito con historia propia. ¿Qué era, no fondo, Galicia? Dos sucesos ocurridos neste territorio ¿cales eran galegos e cales españoles ou mesmo europeos, anque ocurriran neste espacio xeográfico?

Para tódolos nacionalistas, a Historia ven ser o saber fundamental, porque é coñecendo o pasado cando se descubre o eixo da Tradición, se a limpa de adherencias ventureiras e, se cadra, de extravíos. Pero neste punto compre suliñar un matiz notable. Nalgúns dos autores da Xeneración aparece unha curiosa contraposición entre Historia e Filosofía (supoñemos que «da Historia»), entre método histórico e método filosófico. Vai ser unha tese que role duns a outros como un callao por regueiriño montesío. Encétaa Muguía, quen confesa tela recollido do historiador francés Thierry ${ }^{15}$. Conforme a esa contraposición, o método filosófico adáptase para os pobos cun grande papel na historia, depositarios da traslatio imperii $\mathrm{e}$ das Filosofía da Historia tipo Hegel ou Spengler, pero non para o vulgo

${ }^{15}$ Prólogo á Historia de Galicia.

"CUADERNOS DE ESTUDIOS GALLEGOS", Tomo XLVII, Fascículo 112, Santiago 2000. 
das pequenas nacións que non levan o facho da Humanidade, anque son a maioría. Por eso dí el, pensando na súa, que prefería o método histórico, «pues conserva como ninguno el carácter peculiar del pueblo, de los individuos y de los sucesos de que el historiador va a ocuparse». Estamos no que se ten chamado concepto «histórico-orgánico»e tamén «historicista» da nación. Xa na primeira intervención pública de Risco como galeguista neonato, mencionará esta contraposición ${ }^{16}$. Eco serodio de Risco, anque sen citalo, é de supoñer que sexa unha frase que ven solta en Sempre en Galiza: «O concepto de nación é un concepto histórico e non filosófico».

Xa que logo, o sentido da historia de Galicia haberá que buscalo no decorrer dos feitos históricos. Tamén outros países andaban daquela a voltas co tema de topar o seu camiño como nacións (Lémbrese o título de tantos libros: «o problema de»). Rusia e máis España estaban entre os países «problemáticos». A implantación do comunismo fixo pensar a algúns intelectuáis rusos (por exemplo, a Nicolás Berdiaeff) no «destino» da súa patria. É de sobra coñecido o debate en España entre europeístas e casticistas. Polos anos 20 Ortega y Gasset, Ramiro de Maeztu e outros avivaban unha polémica que viña de anos atrás (Menéndez Pelayo, Unamuno). Aquí encaixan dous ensaios de Otero Pedrayo: O Ensaio histórico sobre a cultura galega e máis Morte de Resurreción. Veñen ser como dous grandes frescos ou frisos nos que vemos, en «alto relieve», os persoaxes de "Alba de Gloria», pero inscritos nun fondo que reborda das persoas e entra no decorrer das formas. Unha Filosofía da Historia máis poética que conceptual, se se quere, pero que enxerta a nosa pequena cultura galega no sentido universal da Historia da Cultura. Eran anos en que se lía moito A decadencia de Occidente, de O. Spengler e outros libros de morfoloxía cultural. De todos modos, Otero Pedrayo (seguindo ou coincidindo con Risco) entende o sentido da historia ao modo romántico, como «liberación do espíritu» (Morte e Resurreción), expresión que rima coa visión relixiosa doutros textos deles.

\section{E) FACER DO ENXEBRE UNHA TRADICIÓN}

O gosto polo popular remanecía do romantismo e chegara a Galicia xa no século pasado. Rosalía (Cantares Galegos) ten o mérito de ter sido a

${ }^{16}$ Véxase o meu traballo antes citado «A filosofía política de Vicente Risco» (revista Grial, núm. 86, monográfico adicado a Risco, 1984, páx. 402).

"CUADERNOS DE ESTUDIOS GALLEGOS", Tomo XLVII, Fascículo 112, Santiago 2000. 
primeira en erguer a poesía popular a poesía culta Un Machado, catedrático de A Coruña e pai dos poetas famosos, promoverá entre nos a colleita dos costumes populares; a Condesa de Pardo Pazán presidira a primeira Sociedade Folklorista.

Tamén nesto os da Xeneración van pegar un salto cualitativo. Onde outros vian un pintoresquismo folklórico eles descubren un nivel étnicocultural profundo, cáseque metafísico. Non tratan somente de descubrir diferencias, senón de cultivalas. «Ser diferente é ser existente», diría unha e outra vez Risco, repetindo para as comunidades o que para os individuos proclamara daquela Miguel de Unamuno e, antes, o danés Kierkegaard. Tradición é, para os nacionalistas, a permanencia desas diferencias naturáis e culturáis a pesares dos cambios de circunstancias. Como quen dí, o fio do colar no que se van insertando as sucesivas xeneracións.. «Somentes un pobo que posee o senso da súa Tradición pode ser grande», «un pobo é unha cultura autóctona ou non é nada»: son frases lapidarias de Risco. Non necesitaba nesto ser orixinal: o seu enxebrismo correspóndese co casticismo dos intelectuáis españois xa desde a segunda metade do século XIX (Menéndez Pelayo, Unamuno: Ensayos sobre el casticismo). Neste punto xurdiría un punto de doloroso enfrentamento cando a Constitución de 1931 abandase para o laicismo e, máis en concreto, cando os galeguistas discutisen sobre se entrar ou non na coalición electoral chamada Frente Popular (1935-36). Risco como Otero Pedrayo considerarían que a relixiosidade católica era elemento esencial da tradición galega, tese que non podían aceptar os máis laicistas (Castelao, Antón Villar Ponte).

Cando a Guerra Civil xa deixara fora de xogo político á Xeneración e a cuestión fixérase máis teórica que práctica, Castelao puntualizaría:

"Hai algo que está por riba da historia e que é superior ao pasado: a verdadeira e auténtica tradición de Galiza. Non aquela tradición dos chamados tradicionalistas, que se afinca nos tópicos da Historia e que pretende resucitar tempos abolidos, senon aquela enerxía étnica que vive nos limos da concencia nacional de Galiza e loita por rexurdir e frorecer. Porque a tradición non consiste nunha serie de feitos históricos superpostos nin reside somente no pasado, pois ten asegurada a sua continuidade no tempo. A tradición é a alma eterna de Galiza, que vive no cerne dos nosos instintos e na entrana granítica 
do noso chan. A tradición é o idioma, o arte, o espírito, a cultura, o xeito de vivir e o sentido trascendente da vida e da morte, o afán de universalidade e de encetar camiños inéditos, o amor á xusticia e as boas formas de convivencia, a identificación coa Terra que nos fixo e nos criou. A Tradición é aquelo que endexamáis nos traicionou e que sempre foi traicionada» (Sempre en Galiza).

Non aparecendo unha raza diferenciada e non tendo tampouco Galicia unha tradición de poder independiente -malia a que Murguía insistira nun dubidoso Reino de Galicia na Edade Media-, compría salientar os aspectos culturáis. Daquela inzaba a afición pola morfoloxía cultural. Todos insistirán nos factores culturáis, pero algúns de Xeneración incluirán rasgos peculiares máis discutibles e non sempre por todos compartidos. Así Risco detense no «sentimento da Terra como característico nas súas duas manifestacións antagónicas: dunha banda, o sedentarismo: doutra, a saudade ou "cobiza do lonxe» que leva en dialéctica a emigrar e despois sentir nostalxia da Terra ( $O$ sentimento da terra na raza galega. Nós, 1920). Otero Pedrayo topa como outro xeito diferenciador o anceio de inmortalidade (lémbrese o culto aos «nosos difuntiños», a Santa Compaña, etc): «Na alma galega sentimos todos a presencia dun eixe vital inmorredoiro que nos dá a nosa forma espiritual e nos diferencia das outras xentes habitadoras da Iberia» (Morte e Resurrección). Para Risco, a relixiosidade católica formaba parte do enxebre galego e non aceptaba pactar con antirrelixiosos por conseguir o Estatuto. Como se sabe, ese pacto custoulle ao Partido Galeguista unha escisión moi doorosa ${ }^{17}$.

\footnotetext{
${ }^{17}$ Risco opoñíase a que o Partido Galeguista entrara en coalición electoral coas Esquerdas (Frente Popular) por enxebrismo. Consideraba que os Partidos de esquerda eran centralistas e, ao mesmo tempo, que iban contra un carácter que el consideraba consustancial co enxebre galego: a relixiosidade católica. Máis tácticos e oportunistas, Castelao e outros dirixentes optaron por xogar sobre seguro e conseguir a aprobación do Estatuto. Como se sabe, anque ningún Partido político fixo campaña en contra do Estatuto (todo o máis, a Dereita desentendeuse do Referendum), para conseguir o número de votos necesario necesitouse acudir un chisco a endémica chapuza electoral. Compre advertir que o Estado, para tramitar un Estatuto de autonomía, esixía un porcentaxe de votos difícil de acadar, dado que boa parte da poboación galega vivía en actitude prepolítica. Aínda nos anos 70, non houbo moita participación na votación para os Estatutos de Autonomía do País Vasco, de Cataluña e, por suposto, de Galicia.
} 


\section{CODA}

Como xa se dixo, non eran moi dados a sistematizar as suas ideas nin a debatilas con argumentos e respostas aos argumentos dos adversarios.. Escribían dun xeito claro, sobrio, e somente facían teoría con ocasión dalgún tema concreto. $\mathrm{O}$ esquema panorámico presentado fai posible conxuntar as tesis que eles presentaron soltas e, xeralmente, sin se citar. Tanto como as tesis explícitas importou a rede de coincidencias e congruencias tácitas. Eso implica ter en conta tamén os matices: as insistencias, prioridades,omisións e ausencias.

De ordinario éntrase a estudiar direitamente a ideoloxía política:as demandas de autonomía, o proxecto de Federación Ibérica, o posicionamento verbo dos problemas españois da Segunda República. Pero eso foi consecuencia e podería darse ou non, ser así ou doutra maneira. $\mathrm{O}$ fundamental foi o descubrir a especificidade da etnia galega e movilizar aos galegos cara a autoafirmación no seu.

Fose cal fose o tipo de escrito - relato ou alocución oral ou ensaio- o discurso deles transcurre sempre do mesmo xeito. Un «consciente» móstralle aos seus compatriotas que Galicia débese identificar ad intra e diferenciarse ad extra. $\mathrm{O}$ autor non entra en debate consigo mesmo e os escritos terminan como se os lectores non puxeran obxección nin reparo. Por eso, os dados a examinar pros e contras do nacionalismo, sempre teremos motivo para facer algunhas preguntas. Afirmarse implica ineludiblemente afirmarse contra alguén o contra algunha situación. O nacionalismo ¿non promove as disensións? ¿non vai contra a solidariedade? Cando en todo se vai cara a sociedade planetaria, ¿non van os nacionalistas a contra pe? Segunda: hai cousas como a ciencia, a filosofía, o arte, a moral, os dereitos humáns, que son comúns a tódolos pobos, que son obrigas e dereitos nos que non caben diferencias. ¿Cómo compaxinar diferencialismo con universalidade? Terceira: os nacionalistas propoñen que a cultura universal sea a suma das contribucións peculiares de cada cultura, pero se cada etnia debe cultivar as suas diferencias culturáis, eso significaría deixar a outros aqueles temas que non de ninguén en particular. Se os galegos compoñen muiñeiras e os cataláns sardanas, ¿quén compoñerá a Novena Sinfonía?

Unha prosecución da temática aquí exposta debería comprobar se eles responderon a estas pregưntas e qué resposta deron ou darían no caso de terse prantexado esas cuestións.

"CUADERṆOS DE ESTUDIOS GALLEGOS", Tomo XLVII, Fascículo 112, Santiago 2000. 